Wordlength 7,652.

\title{
To what extent are Teaching Assistants really managed?: 'I was thrown in the deep end, really; I just had to more or less get on with it'.
}

Abstract

The main aim of this research was to secure a better understanding of how Local Authorities (LAs), Senior Leadership Teams (SLTs) and teachers in state schools perceive their responsibilities for the deployment, leadership and management of teaching assistants (TAs). Current research in the field - some of which has been highly influential on policy - has largely focussed on aspects of TA performance and pupil attainment. Importantly, we have chosen to investigate how TAs and SLTs themselves describe their experiences of management.

A total of 71 teaching assistants, together with teachers, senior leaders in primary schools and LA advisors across two Local Authorities, were surveyed. Based on 55 questionnaire responses, 11 interviews and a focus group $(n=5)$ we found evidence of a dislocation of management priorities for effective TA deployment. What emerged was a strong sense of 'otherness' felt by many TAs, who believed themselves to be dissociated from their own management. We conclude that TAs make up a workforce that appears to be closely managed but which is in fact often poorly led, resulting in feelings of detachment.

Keywords: Teaching Assistants; School Leadership Teams; Local Authority; management; control; otherness. 


\section{Introduction}

The continued importance of teaching assistants (TAs) helping to support learning in English classrooms is being closely examined, in austerity times, by both Her Majesty's Treasury and the Department for Education (DfE). Indeed, Lepkowska (2013) reports that planned cuts to the national Education budget may result in the removal of 240,000 TAs from the school sector. Such drastic reductions might be considered reactionary, but are clearly linked to the challenging findings of government commissioned research into the educational and financial value of TAs (see the Deployment and Impact of Support Staff report (Blatchford et al 2009), and the Effective Deployment of Teaching Assistants (EDTA) project (Blatchford, et al 2011)). The EDTA project tested models of TA deployment and concluded that TAs had, at best, only modest positive impacts on pupils' learning. In the light of such findings, maintaining the status quo of TA deployment in schools will apparently not raise pupil attainment - the recent sharp decline in the numbers of TAs employed in secondary schools may not be unconnected.

The Department for Education (DfE) (2014, p. 15) regularly re iterates that schools:

'are responsible and accountable for the progress and development of [all]

pupils, including where pupils access support from teaching assistants'.

The necessity for expedient management of TAs is also acknowledged in the SEN/D Code of Practice (DfE, 2014). The research reported here explored the responsibilities of two Local Authorities (LAs) in the English Midlands to communicate effective management and deployment practices for TAs to Senior Leadership Teams (SLTs) in primary schools. We focused on how TAs and SLTs report their experience of management, analysing our data against the themes first identified in the Wider Pedagogical Role (WPR) model (Blatchford et al 2012). It became apparent that TAs believe themselves to be a beleaguered group of employees compared to other school staff, feeling a sense of 'otherness' with respect to their training, management, leadership and day-to-day work. 
At the turn of the century the UK Government recognised the need for greater consistency in the management and training of TAs, publishing 'good practice guides' (DfES 2000) and consultation documents for schools (DfES 2002). Ofsted (2002) similarly recognised the 'tremendous contribution that well trained and managed teaching assistants (TAs) could make in driving up standards in schools' (p.436), proposing that skilled deployment was the key to maximising TA impact. However, over the last decade concern about the effectiveness of TAs has grown. The DISS report (Blatchford et al 2009) gave rise to increased scrutiny of TA roles by schools, academics and policy makers although significant research into how SLTs manage TAs, and how LAs contribute to this process, remained largely unchartered. Mahmoud (2011) highlights a lack of empirical evidence in this regard, commenting on how TAs essentially 'manage themselves' - with some even being unaware of who their line manager is.

\section{Roles, modes of deployment and management of TAs}

With respect to the administration of TAs, Watkinson (2003, p.165) observes - perhaps selfevidently - that:

'TAs are only as effective as their use, deployment and management'.

But how has the role of the TA developed over time, and what are their current management and training needs? The presence of another adult in the classroom is by no means a modern construct. In the 1960s, Plowden (1967) noted that classroom assistants were being used to support 'under resourced' teachers. This workforce was regularly referred to as a 'Mums' army' (Bladen 2008), providing general assistance to primary school teachers and helping with practical tasks such as 'cutting and sticking'. Following the Warnock Report (DES, 1978), and the 1981 Education Act (DfES 1981), the recruitment of 'special needs assistants' in English schools led to a substantial increase in TA numbers - often employed with more clearly defined roles (Swann and Loxley, 1998). From the mid-1990s to the end of the first decade of the 21st century the number of TAs working in English 
and Welsh classrooms more than trebled (from 60,600 in 1997, to 213,900 in 20101), accounting for nearly one quarter of all teaching-related staff in schools. Two policy shifts explain this dramatic upsurge in TA employment: firstly, New Labour's 'Every Child Matters' agenda (DfES 2004), which resulted in the recruitment of assistants to support children with Special Educational Needs (SEN); and secondly, the Workforce Reforms of 2002 (DfES, 2002), which were aimed at addressing the teacher retention and recruitment crisis, partly through the employment of para-professionals.

Defining the nature of TAs' work has always been complex. In the early 1990s, Clayton (1993) suggested a subtle shift in many TAs' roles from being 'teaching assistants' to becoming 'assistant teachers'. The UK government championed the growth in numbers of assistants in the classroom, whilst seeking to offer greater role clarity through the 2002 Education Act (DfE, 2002) - which recognised that although the majority of TAs did not actually 'teach' they nevertheless made a 'substantial contribution to...teaching' (although the precise nature of this contribution was not elaborated). As a consequence the DISS report highlighted considerable variation in TAs' roles, reflecting Kamen's (2003, p.1) observation that 'adults working in the classroom' have a range of titles including:

'learning support assistant, classroom assistant, special needs assistant, non-teaching assistant 2.'

Cremin, et al (2005) also stress that TAs' roles have changed from being 'helpers' to having greater responsibilities for the learning outcomes of the pupils they work with. The DISS report (Blatchford et al 2009, p.4) states that 'there is much debate about the appropriate role of support staff in schools', whilst Dymoke and Harrison (2008, p.140) suggest that there is no concrete definition of the role of the TA since this is 'most likely determined, or negotiated, at individual school level'. Although such flexibility allows schools to define TA deployment as they see fit, it also leads to

1 Source: House of Commons (2011), Hansard written answer 9.9.11 (Hansard figures have been checked against consecutive government statistical first releases. Figures vary slightly, but the increase is consistent against all records).

2 Additionally, the terms 'Special Support Assistant' and 'Specialist Teaching Assistant' are also common. Use of the generic term 'Support Staff', rather than 'teaching assistant', in government materials may further illustrate perceived variations the roles of TAs. 
anomalies in job descriptions and differing expectations of management and leadership. The lack of understanding of what TAs do was highlighted by Gunter (2007, p.31), who claimed that research into their effectiveness was mostly anecdotal and 'impressionistic' rather than grounded in hard evidence. She asserted that data was either not available, or was not being used effectively enough, to deploy and manage such staff (Gunter 2007).

Review of government literature yields very little specific guidance about TA deployment and management. Publications on school management (such as Everard, Morris and Wilson 2004, Watkinson 2003, 2008, Blatchford, Russell and Webster 2012, HMI 2002) provide more specific information, but often fail to recognise the increasing organisational responsibility of the SENCO. Guidance to heads regularly fails to recognise the budgetary implications of deploying and training TAs, a significant omission given the reductions in earmarked finance to most state schools. Goepel and Sharpe (2014) summarise these difficulties: 'guidance has been slow to be introduced, leaving schools feeling rudderless and uncertain as to the direction they should be taking' $(2014$, p.9). In this respect, it is useful to consider how para professionals in other contexts are deployed to understand whether their management is fraught with similar frustrations as in the field of education.

\section{The Deployment and Impact of Support Staff (DISS) Report}

The Deployment and Impact of Support Staff report (Blatchford et al, 2009), and further research subsequently undertaken by those involved in this project (Blatchford, Russell and Webster 2011, 2012), has strongly influenced government perceptions of the value of TAs (see Fletcher-Campbell 2010, Giangreco 2010). Such evidence-based research reveals that TAs are not being deployed effectively. The project was commissioned to 'obtain reliable data on the deployment and characteristics of support staff' (Blatchford, Russell and Webster, 2009, p. 1) and to assess their impact on pupil outcomes in England and Wales, as: 
'the largest study yet undertaken on support staff (involving) a large-scale

nationally representative questionnaire survey involving nearly 18,000

responses' (Blatchford et al, 2009, p.1)

The scale, resources, theoretical frameworks and project design validate the DISS research in terms of its production of high quality data (as expressed in the EPPI review, by Alborz et al 2009), but findings may still be open to interpretation. Importantly, the report highlighted a negative correlation between TA support and pupil progress - while also noting the increasingly pedagogical nature of most TAs' roles. However, it acknowledged that the lack of pupil progress was not necessarily solely the fault of the TAs themselves or indeed the teachers who managed them, rather it was a result of:

'(the) decisions made by school leaders and teachers about how their support staff are used and prepared' (Blatchford et al 2009, p.1).

DISS has therefore provided a wealth of information about the characteristics, conditions of employment, preparedness, deployment and practice of TA, but has not sought to find solutions to issues. It simply concludes that TAs are operating sub-optimally, affecting their positive impact on pupils' learning. Smaller-scale studies arrive at similar findings (see Watkinson 2003, Butt and Lance 2009, Dillow 2010). However, the conclusions from these studies have neither achieved universal support, nor agreement - indeed Elkins and Grimes (2009) do not concur that the overall responsibility for TA management should lie with SLTs alone:

'the active participation and achievement of every member of the school community is seen as fundamental to the ongoing successful development of the whole school' (p.18).

It was in part a desire to pursue further the concerns identified by such research that stimulated the research work reported here.

\section{The Effective Deployment of Teaching Assistants (EDTA) project}


Following the DISS review, the Effective Deployment of Teaching Assistants project (EDTA) - which involved forty teachers and TAs, from ten schools, in two local authorities - sought to illustrate 'best practice' in deploying and managing TAs. The project was designed by Blatchford, Russell and Webster (2011) specifically to 'address the startling results from the ...DISS project' that 'children who received the most support from...TAs made significantly less progress than similar pupils who received less support' (Blatchford et al 2009 p.2).

Like the DISS report, it illustrated that the majority of misunderstandings about the deployment of TAs arise from different perceptions of their roles. The UK's Coalition government (2010-5) viewed role clarification as essential to the management and deployment of TAs by SLTS (NASUWT 2014), regarding the freedoms afforded head teachers and SLTs as having led to inconsistencies and unacceptable variation in practice. Although the EDTA project's recommendations reinforced the DfE's view that 'school leaders are best placed to make decisions' (DfE, 2011), there remained strong arguments for a more formal, standardised approach to the local management and training of TAs. In the current political climate, with the removal of funding from many LA services, schools are increasingly responsible for implementing their own 'framework for change' (Blatchford, Russell and Webster, 2011 p.54). This has led to a widening of standards and a training gap. The most successful models of TA management appear to have occurred in schools where SLTs have previously collaborated with their LAs to share good practice, with the report asserting that 'some practitioners - from NQTs to experienced teachers - would benefit from retraining to change their views on TAs and their own roles, especially towards pupils with SEN' (Blatchford, Russell and Webster, 2011, p. 53).

These two influential reports, together with findings from the Sutton Trust (see Higgins et al 2013) and the think tank Reform (Thorpe et al 2013), consider TA deployment to be 'high cost, but low impact'. They indicate that while successive governments have traditionally funded and supported 
the growth in numbers of TAs in state education, this has not been accompanied by clear guidance and training about how TAs should be managed and deployed to maximise pupil attainment.

\section{Managing TAs}

In 2004, Pyke highlighted the pressing need for teachers to become proficient in the management of their teaching assistants (Pyke 2004), while Lowe and Pugh (2007) subsequently raised questions about how this might occur. Butt and Lance (2009) took such work further by examining the modernisation and remodelling of the whole school workforce, choosing to focus on a sample of primary schools in Shropshire which promoted 'innovative use of TAs' (p.222). Despite this local authority reportedly enjoying success in deploying TAs, Butt and Lance concluded that their continued effectiveness 'could not be successfully achieved without the benefits of further professional development' (Butt and Lance, 2009, p.226). Indeed, they assert that:

'Distributed leadership models have resulted in TAs being managed by a number of different individuals in schools causing both confusion and duplication of effort' (Butt and Lance 2009, p.228).

This research highlighted significant gaps in TA management and the existence of unhelpful, wide ranging, job descriptions. Pugh (2007) similarly noted the range of management models for TAs and attributed a lack of consensus about TA deployment to the mismanagement of their roles.

As expectations of TAs' contributions became more demanding - with responsibilities increased by the introduction of the National Literacy and Numeracy Strategies, the new National Curriculum, and more exacting standards to be achieved - the idea of introducing qualifications for TAs was explored. Under the New Labour government (1997-2010) TA training was recognised as an area of significant neglect, which the DfES sought to remedy by introducing a selection of vocational qualifications 3.

3 Levels of qualification for TAs were introduced as follows: Level 1 Teaching Assistant (entry level), Level 2 Teaching Assistant, Level 3 Teaching Assistant, Higher Level Teaching Assistant (HLTA), and Foundation Degrees in Education. 


\section{The impact of the SEN/D Code of Practice}

The SEN/D reforms (DfE 2014) have further influenced the ways in which TAs are expected to work. However, although class teachers and SENCOs are required to take on greater management responsibility for TAs within the classroom, guidance that accompanies the Code places the main responsibility for educational provision for children with special educational needs firmly with their local authorities. It notes that:

' $f 70 m$ has already been allocated to local authorities in 2014-15 through the SEN/D Reform Grant' (DfE 2014 p.1).

This Code does not specifically outline how LAs are expected to manage and apportion this budget. Parents of children with special needs can make financial claims, as must schools, resulting in various budgetary issues - which have further complicated the ability of LAs and schools to deploy TAs appropriately. Here is a system in which 'the local authority should provide strategic oversight of SEN locally', although much of this responsibility is effectively devolved to schools. The DSG (Dedicated Schools Grant) includes a national budget for pupils with SEN, but it is unclear how much should be allowed to filter down to schools for the employment, training and development of teachers and teaching assistants. If the SEN/D Code of Practice (2014) effectively removes close budgetary control from LAs, it also leaves them largely impotent to lead effectively. As Wright and Kersner (2001, p.280) reminds us:

'Leadership ... for the direction of schools is being removed from those who work there. It is now very substantially located at the political level where it is not available for contestation, modification or adjustment to local variations'.

Additionally, the Code of Practice places greater responsibility on teachers, TAs, SENCOs and SLTs to account for the progress and development of all pupils, but: 
'Where support staff work with pupils with SEN, the teacher has overall responsibility for those pupils and must ensure that they make appropriate progress' (DfE, 2014) (our emphasis).

The Code states that 'every teacher is a teacher of SEN' and infers that the development of such pupils must sit at the heart of each school's performance management agenda 'and its approach to professional development for all teaching and support staff' (NASUWT, p.2) The implications for schools are therefore considerable in terms of future allocations of time and money. With further reforms, most notably to assessment and the national curriculum, SEN/D has meant that 'School leaders and SENCOs will be under substantial pressure [and]... may fail to provide strategic direction' (NASUWT 2014), particularly in the wake of support staff cuts. The reforms have also highlighted dramatic changes to the role of the SENCO, who has not traditionally been part of each school's SLT. Whereas previously SENCOs have largely held administrative responsibilities, such as writing 'statements' for children, the Code advises that they should now form part of the SLT and adopt a more 'important strategic roles within a school'.

\section{Objectives}

We have recognised that only modest evidence exists about how TAs' roles and responsibilities are understood, managed and led by SLTs and LAs. Our main research objectives were therefore to:

- Examine the perceptions that LAs, and in turn school SLTs, have of their role as managers of TAs in mainstream primary schools in England.

- Understand the importance of the role of SLT in light of the decentralisation of LAs; where responsibility has been devolved to local schools to make decisions about TA training and deployment.

- Understand how TAs and SLTs experience management. 
- Examine the effects of variations in training and deployment of TAs on working conditions and pupil experience.

It has been suggested that 'careful management' of TAs is a key to their successful deployment (Booth and Ainscow 2002, Elkins and Grimes, 2009), but Mahmoud (2011) highlights a lack of existing empirical evidence on such management (her research focuses predominantly on how TAs manage themselves, rather than on how they are managed by others). Our enquiry examined such issues through the consideration of the work of two local authorities, to explore if the LAs and schools were aware of the findings of the DISS and EDTA reports and, if so, whether they were choosing to act upon them.

\section{The decision to use the voices of LAs, SLTs and TAs}

The voice of SLTs and LAs has traditionally been absent in much of the policy debate about the role of TAs (Mansaray 2006). Whilst SLTs are mentioned in the DISS and EDTA reports, and in subsequent research literature, school leaders were simply asked about the role of the TA within the classroom. Current literature therefore largely ignores the voice of the TA and fails to create a forum through which perceptions of everyday management can be expressed. Significantly, the DISS team stated that they 'did not include TAs' in their working groups since the aim of their research was to 'develop a dialogue ... with staff with decision-making responsibilities at the classroom and school level' (Blatchford, Russell and Webster, 2012, p.120). The utility of directly exploring TA experiences has therefore been underplayed. For example, Dillow (2010) focuses on 'ethnographic' and 'autoethnographic' portraits of TAs, but his findings are arguably too personal to be used to draw systematic and rigorous conclusions. Indeed, there is no sustained analysis offered for these 'stories'. Mansarary's (2006) small-scale qualitative study, using observation and semi-structured interviews in two schools, sought to use a more 'scientific' approach to giving TAs a 'voice' (p.173), but does not attempt to offer generalizable data. 


\section{Conceptual framework}

The conceptual framework within which the respondents' comments were analysed in this research, was borrowed from previous work by Bullock et al (2010) and Butt and Macnab (2013). Their models sought to position different professional groups with respect to who controls the content and mode of their CPD provision (see Fig 1). However, these models were easily altered to illustrate the positioning of TA leadership and management - that is, whether the TA (individual) has significant working autonomy, or is predominantly led/managed by another (external) member(s) of staff (Fig 2).

Fig 1: about here

Fig 2: about here

Here we theorize that the majority of TAs sit firmly within the quadrant labelled 'controlled' - having 'external' controls over the ways in which they work (directed by classroom teacher, SENCO, head teacher, etc), as well as in what they do (supporting learning, general classroom tidying, administration and so forth). By contrast classroom teachers - according to their various schools, career stage, policy and curriculum diktats - might be better positioned in any of the other three quadrants; having some autonomy about the ways they work and what they do in the classroom (which might be termed 'regulated', 'managed', or in some cases where the classroom teacher has the locus of control, 'liberal'). This, we hypothesised, might have some effect on the TAs' sense of 'otherness' and on their perceived status within schools.

It is interesting to map how the positioning of both TAs and classroom teachers has shifted, and may shift further in the future. We believe that TAs have always sat within the 'controlled' quadrant, even if their status was elevated as a consequence of promotion to HLTA status - whilst many teachers may have moved to more regulated and managed work, away from the liberal quadrant. It 
is, however, worth noting that this rather simplistic model almost certainly oversimplifies the complexity of situations experienced by teachers in their different school contexts.

What we believe transpires from our research is that TAs are not really 'managed' - they have little individual or collective say in the ways in which they work, or in what they are expected to do. However, they are also not necessarily a 'controlled' group either, as this suggests a closeness and directness of management that most TAs rarely experience.

\section{Methodology}

In devising the methodology for this research, studies with similar objectives were considered. Data was gathered through interviews, focus groups and questionnaires over a period of two years - the pilot study taking place before the SEN reforms became statutory in 2014 , and the study proper being conducted after their introduction. It was triangulated by examining the management structures of the organisations in which the data collection took place. It could be argued that a richer selection of data could have been achieved using classroom observations, to cross reference claims made by management and teaching assistants about the ways in which they were deployed. However, it was felt that an analysis of planning would provide an equally robust and possibly more efficient way of gathering and interrogating the data. Whilst interviews are sometimes perceived as overly 'directed' (O'Reilly, 2009, p.78), the aim of this research was to examine the 'understandings and priorities' (Pole and Morrison 2003, p. 35) of participants - best achieved through the use of semi-structured interviews and focus groups.

Two School Workforce Advisors were interviewed from the two LAs to determine how government policy on TAs had been interpreted at local level. The findings were further examined by interviewing SLT members and TAs from six primary schools in these authorities. The interviews sought to understand the perceptions of leaders vis-a-vis their management responsibilities. A questionnaire was given to TAs from the schools to understand their perceptions of management, 
how they were managed, and how well they believed they performed and responded to this management. Exploratory data analysis (EDA), advocated by Myatt (2007), was used to analyse and triangulate these findings with the interview data.

The focus of this study is the primary school sector, where SLTs have arguably gained more experience of working with TAs than their counterparts in secondary schools (Klassen, 2001). Previous research, by Clark et al (1999) and Butt et al (2005), has noted that TAs' roles were less clearly articulated in the secondary sector, often mirrored by a lack of effective planning.

\section{Findings}

Our research findings, for ease of comparability with previous work, are presented under the same themed headings as those used in the WRP model (Blatchford, Russell and Webster 2012) - namely, characteristics of employment, preparedness, deployment, and practice of TAs:

\section{- Characteristics of Employment}

Of the 55 TAs surveyed, ten $(6 f, 4 \mathrm{~m})$ were interviewed, of whom seven already possessed level 2 or 3 BTEC qualifications, two were HLTAs and one had no qualifications. Interestingly, three of the cohort were also students on the first year of a BEd degree, and one was awaiting confirmation of a place on a SCITT - these were individuals in their twenties, much younger than half the cohort (who were predominantly in the age range 40-51). Essentially this group was similar in background to those who took part in the DISS (2009) research, but with a larger proportion of younger (21-31 years), more highly qualified, staff (with $87 \%$ possessing qualifications at NVQ level, or above). The interviewees were therefore not closely representative of the population of TAs in England, and their levels of qualification countered Cremin et al's (2005) earlier concerns about this criterion. Hancock and Eyres (2004), at around the same time, also noted a qualification issue, referring to TAs as 'cheap and readily available ... labour' (p.231). These points may still apply nationally, but our 
cohort appears to reflect a growing trend in recruitment of staff who either already possess or aspire to higher qualification levels, possibly en route to becoming teachers.

TAs' responses about the characteristics of their work were collated within the following themes: routes of entry to becoming a TA; pay, hours and conditions of service; and training. Reasons given for entering the profession were varied, but often reflected the grasping of an employment opportunity - either as a 'stop gap' between other jobs, or as a more considered step towards becoming a teacher :

'when my son started school the nursery staff asked me if I was interested in covering for an hour, and it progressed from there' $(\mathrm{TA}, \mathrm{f}, 1)$

'this is just a stop gap; I tried to get onto some teaching courses - but they were all full' $(T A, m, 1)$ 'when I left uni I didn't really know what to do; my mum is a TA and she said there was a space for someone in her school. The head was impressed with the work I was doing and helped me apply for some SCITT programmes - I've been accepted for next year' $(T A, m, 2)$

Consistent with DISS (2009) findings, female TAs often stated that they had gained their post 'organically' - through volunteering, or by obtaining employment in their child's school for convenience reasons. Employment as a TA was often an expedient 'means to an end', rather than a more conscious and considered career move. Without exception all the young male TAs were either training to be teachers, or were awaiting acceptance onto ITE courses (both LAs had considerable levels of ITE provision). There therefore appear to be significant differences in the motivations and employment aspirations of our cohort - which arguably reflect different expectations of the ways in which they would subsequently be led, managed and trained. Respondents were acutely aware of the poor levels of pay, loose conditions of service and irregular hours associated with the work of a 
TA. For some this was highly de-motivational, meaning they had little incentive either to train or to seek advancement in their role.

With respect to conditions of employment, TAs remain the least well-paid of all staff in schools that have a pedagogical role - with many reporting working additional hours without pay. This is, of course, a situation typical for many para professionals elsewhere (health, dentistry, police, law, etc.).

\section{- Preparedness}

Whilst not enshrined in legislation, Ofsted (2012) expects schools to provide planning time for 'other adults' in the classroom - the EDTA report (2011) mirrors this expectation. A quarter of TAs in our research cohort were afforded planning time with their class teachers, the SEN/D reforms having made negligible impact on practice despite the now statutory requirement that teachers be given planning time with TAs if they are supporting SEN children. The situation faced by most TAs was therefore not positive:

'We do plan with the teacher, but this will be after or before school - for which we are not paid' $(T A, f, 2)$

'A lot of teachers, in all fairness, have relied heavily on their TAs and although they've given them planning (time) have not really appreciated their skills' $(H, m, 1)$

If preparedness is closely equated with planning time, training opportunities, provision of consistent and helpful feedback, then most TAs in our survey could not be considered to be fully prepared. Planning time was regularly described as being 'flexible', taking various forms - indeed, planning arrangements were defined in different ways by SLTs, with planning processes showing marked inconsistencies between schools. LA advisors acknowledged the problems of establishing joint TA and teacher planning, but largely felt themselves powerless to intervene. One headteacher revealed what amounted to 'lip service' with respect to the need for joint teacher and TA planning: 
'we made an adjustment a couple of years ago, to bring the start of the 'class based' TA hours forward to 8.30am in the morning. That is the time that all staff are in the building ... which gives teachers and TAs at least 10 minutes together' $(H, m, 2)$

A TA working in the same school commented:

'some teachers are a lot more considerate of your time than others. Some plan interventions, so I don't have any planning time ... it depends on the teacher' $(T A, f, 3)$

Teachers interviewed often claimed they had received little or no training in how to manage their TAs, from their pre-service training to the present day. This mirrors the findings of the Making a Statement project (MAST) (Webster and Blatchford 2015), although again this did not directly access the views of SLTs and LAs. A disparity therefore seems to exist between SLTs' perceptions of planning time given, and what TAs describe of their work - with one headteacher boldly stating 'they've had all the training [for planning] they need' $(\mathrm{H}, \mathrm{m}, 3)$. More positively, when asked about receiving 'feedback' on their work, around half of the TAs reported that they did indeed get this with $41 \%$ describing feedback as occurring 'often', and with all respondents saying that their managers 4 were available to meet them if they had issues.

Our research found that TA training had increased post SEN/D (2014), 64\% of TAs now reporting that they received 'regular training', compared with only 31\% pre 2014. Further research is needed to establish the quality of this training, and its parity between different institutions. One TA interviewed stated that training 'could be a five minute briefing from the class teacher'. Some heads claimed that older TAs did not want or require training, with both parties seeing training as a low priority. SLT members stated that difficulties with training included reduced LA support, and drastic reductions in funding for training from government since May 2010. Schools are now, of course, expected to bear the majority of their training costs. With respect to preparation and training one TA rather alarmingly commented:

4 The plural reflects the common situation of TAs claiming they had two managers - the classteacher and the Headteacher. 
'I was thrown in the deep end, really; I just had to more or less get on with it'. (TA, m,

2)

LAs' powers to shape how TAs are led, managed and trained in schools have clearly diminished. The LA advisors stated they were no longer the main providers of TA training, although interestingly they gave the impression that they still provided good systems for TA management - a situation not generally reflected in the views of headteachers, teachers and TAs. Data shows significant differences between management and leadership, with much delegation of these roles from SLTs to teachers.

\section{- Deployment}

Blatchford, Russell and Webster (2009) previously noted that TAs were sometimes unable to identify who their line managers were, leading to deployment problems. We asked similar questions and found that all respondents were able to identify their line manager(s), who had often changed recently $-40 \%$ now identifying their SENCO in this role following the SEN/D reforms. This shift in responsibilities was reportedly not always well received by the SENCO:

'at the beginning of term we had a staff meeting. We were told that it was now the job of the SENCO to manage the TAs. Our SENCO was shocked to hear this, you could tell she wasn't prepared for it and to be honest I don't think she's management material' (TA, $f, 4)$.

Post SEN/D fewer TAs identified their headteacher as their line manager (down from $19 \%$ to $11 \%$ ), although male TAs in our sample disproportionately named (male) headteachers as their manager. Class teachers were regularly identified as leaders ( $56 \%$ and $43 \%$ respectively across the two studies); the reason for having two managers was exemplified by one TA, who stated: 
'the class teacher wouldn't be able to book me on courses, although she'd definitely recommend courses to me ... I would then have to talk to members of senior management' $(T A, f, 5)$

Most TAs described their work as 'to do what the teacher asks' (46\%), or 'to work with groups during teacher led activities' (40\%), with 'administration' and 'one-to-one work with pupils' each attracting only $7 \%$ of responses (the 'Other' category was not used by any respondents). This data masks a range of other activities - such as behaviour management, different types of administrative duties, and delivering targeted interventions. Sharples, Webster and Blatchford $(2014$, p.5) state that 'TAs should not be used as an informal teaching resource for low-attaining pupils', although there is much evidence from our research that this is still the norm.

\section{- Practice}

In 2003 Pearson et al (2003) identified that TAs' roles reflected 'an unhelpful level of variation in practice, creating possible areas of misunderstanding and conflict between staff' (p.86). When asked to define their roles in the initial questionnaire survey, TAs responded as follows: 'assisting the teacher' (36\%), 'working with SEN pupils' (29\%), 'behavioural support' (21\%) and 'cover supervision' (11\%) - revealing somewhat different notions of their prime role, a situation also evidenced in the interviews. This variation in role was also apparent in the titles given to TAs by their schools (with categories other than 'TA' being indicated by $21 \%$ describing themselves as 'behavioural support assistants', and $11 \%$ as 'cover supervisors'). TAs in Early Years settings saw their roles as largely synonymous with that of the teacher. One headteacher illustrates the issue:

'when I interviewed 40 applicants for the role of TA that I had advertised, I asked each of them what they thought the role of the TA was. Unequivocally they answered 'to assist the teacher'. I was amazed, in my opinion the role of the TA is to assist pupils in their learning journeys. That is when I realised we had to implement change. 
Since September 2015 we no longer have TAs, we have 'Learning Support

Practitioners" $(\mathrm{H}, \mathrm{m}, 3)$

This head claimed that this had forced TAs, teachers and line managers to rethink the assistants' role and to plan accordingly, although if this is merely a matter of semantics it may lead to further role and practice confusion. Ofsted (2012) assume TAs will have a pedagogical role, but there is clearly still a need for schools to build a shared understanding of responsibilities (Elkins et al 2009).

Day to day management largely occurred through class teachers, but when interview and questionnaire responses from TAs were triangulated with schools' leadership diagrams and policies there was much variation and confusion about the TAs' roles and the expectations of management.

Some TAs descriptions of management were positive:

'I have regular meetings with the pastoral manager so that I know exactly what is needed to fulfil my role, and to talk about issues and concerns' (TA, f, 4)

'My manager is brilliant, she is supportive - but due to their workload we cannot have designated time to discuss issues; it's always 'on the hoof' (TA, f, 5)

Some negative:

'It's difficult to be motivated in your job when SLT don't even bother talking to you. They only really have time for you if you do something wrong. Why should I put in any more effort if that's how I get treated?' (TA, f, 6))

SLT responses were similarly equivocal:

'I would say the (classroom based) TAs are managed by the deputy, and my pastoral manager for the intervention team' $(H, m, 1)$ 
'there is no straightforward answer to this question. Sometimes it's the class teacher ... others work under the direction of the senior leadership team' $(H, m, 3)$

The issue of training was raised. Thornton and Hedges (2006) and the DISS report (2009) point to the importance of teachers and TAs working as a team and the need for joint planning time, but noted the lack of facilitative training. The DISS report (2009) is explicit when it states:

'More needs to be done to prepare newly qualified and in-service teachers with the necessary skills and preparation to help them manage the growing numbers of support staff with whom they work' (p.10)

It was apparent that SLTs were prepared to spend money on training teachers, but not on TAs.

The need for communication and feedback also appeared paramount. In one school the head stated:

'We give feedback to our teaching assistants on a monthly basis. We have a monthly meeting with them and we go over any new policies or procedures and it's also the time for them to air any grievances they may have' $(H, f, 1)$

A TA in the same school corroborates this:

'We feel valued when we're given feedback on what we're doing. That's an important part of our job. If we know what worked well that helps us .... we know what we're doing matters to the senior leadership team' (TA, f, 5)

However, if the communication is one way, rather than discursive, this is invariably problematic.

\section{Discussion}

The Wider Pedagogical Role (WPR) model, devised by Blatchford, Russell and Webster (2012), has summarised the findings of the DISS report (2009) and has been widely cited in educational research as providing a benchmark for the work that TAs do in supporting pupils. The predominant themes of 
the WPR model - characteristics, preparedness, deployment and practice - were therefore used to frame the thematic enquiry of our data.

The first section of the WPR report (Blatchford, Russell and Webster 2012) explores the practice of TAs, concluding that assistants prioritised task completion over learning; were reactive rather than proactive, and often closed down - rather than opened up - discussion with learners. The results of our study revealed similar practices. The research data identified over a third of TAs working towards a teaching qualification and SLTs reporting that most TAs were well versed in enhancing pupils' learning.

With regards to deployment of TAs, the WPR model states that the majority of TAs have a direct instructional, frontline, pedagogical role - routinely supporting lower attaining pupils and those with SEN. This is typified by supporting pupils one-to-one, or in groups. Often this involves instruction, with pupils separated from their teacher and released from the mainstream curriculum. Our research showed that these activities remain, partly because teachers, as Watkins (2003) observed, feel themselves ill-equipped to deal with the demands of many of their SEN pupils and pass this responsibility on to their TAs.

The research presented here found that teachers were still largely untrained in the intricacies of TA management and often struggled to ensure TAs' effective deployment and preparedness for work. We observed on several occasions that TAs were informed at the last minute of the class, or the children, they were to be working with - giving them little time to prepare. As a consequence, Blatchford et al (2012) noted that many TAs spent lesson time simply sat next to a child. From analysing teachers' planning our research demonstrates that many schools did plan TAs' activities (demonstrated in lesson plans where there was a box for recording the deployment of the TA). Unfortunately TAs claimed that they did not receive such plans in enough time to be able to render this information useful - often reporting that they only saw lesson plans two minutes before they were to undertake a lesson. We would argue that there is a managerial responsibility to provide 
time for TAs to plan with teachers, ensuring the effective deployment of both parties. Whilst Blatchford et al (2012) claim that limited subject and pedagogic knowledge are a hindrance to effective TA deployment, our research shows TAs increasingly being recruited for their 'specialist' knowledge of aspects of SEN. However, it is worth asking what constitutes 'specialist' knowledge and to comprehend how this 'knowledge' was obtained (through courses, specialist training, or gaining qualifications).

The final element of the WPR model outlined by Blatchford et al (2012) concerns the TAs' conditions of employment. In addition to responses about pay, expectations of service, hours worked and tasks completed, other indicators of conditions of employment may be gathered. For example, the expectations of TAs to engage in performance management (and their apparent willingness, or otherwise to do so) can be read as a condition of employment. TAs are the second most expensive resource (after the teacher) in the classroom, but their apparent resistance to comply with performance management processes - as evidenced in interviews with SLT members - suggests that this may be regarded by TAs as an unacceptable condition of employment. We would argue that such resistance suggests that the status quo in relationships between TAs and management will continue. A yardstick measure of TA effectiveness, and by implication their successful deployment by SLTs and LAs, is pupil progress. Measuring and analysing this is fraught with issues, and progress can never be ascribed just to TA input, as they work in tandem with teachers and other staff. Performance management of TAs, and indeed teachers, is therefore fraught.

The notion of 'otherness' becomes important when analysing the experience of those who might be classified as either in the 'majority' or 'minority' of school staff, with TAs occupying the latter group. Different sectors of society are effectively controlled by those who have greatest managerial, economic and/or political power; TAs, in the school context, are observed to be largely powerless and lacking a significant voice. By applying the concept of 'the other' we followed the practice of sociologists, seeking to place a critical spotlight on the ways in which TAs' social identities were 
constructed. Such identities are shaped through interactions with others and by subsequent reflection about who we think we are. In our data analysis we decided not to identify individual characteristics, or personalities, of different individuals (generally the focus for psychologists) but adopted the sociologists' focus, which Taylor (1992, p.177) describes as 'the stance of disengagement towards oneself'. This is also a position taken by Lehane (2016) in her research on the TA voice. Social categorisation helps to formulate our ideas about who we think we are, how we want to be seen by others, and the groups to which we belong. In this case, TAs often felt themselves under-valued, under-used and (in extreme circumstances) worthless - clearly a controlled, 'other' group. When TAs felt valued, and perceived themselves to be making a difference, they were often more productive and willing to contribute positively to the school.

\section{Conclusions}

Much research into the deployment, management and leadership of TAs has focused on what assistants do in the classroom - less information exists about the ways in which they are managed, or indeed how they respond to such management. Few studies have interviewed TAs and SLTS explicitly to understand this relationship. The research reported here provides empirical data which helps us to further understand TA deployment, but is mindful that many respondents' statements are anecdotal. Booth and Ainscow (2002), and Elkins et al (2009), reiterate the need for TA management to be examined. As Ofsted (2012) focuses its judgements on pupil outcomes via the effective use of 'all adults within the classroom', LAs and SLTs must take responsibility for effective management of TAs more fully into their remit. The EDTA report (Blatchford et al, 2011) stated that 'the impact and practice of TAs needs to be seen in terms of decisions made about their deployment' (p.1) - these decisions are clearly beyond the control of the TAs themselves.

Much good practice exists, with our work discovering examples of headteachers who actively promote their best TAs, and of TAs whose responsibilities appear interchangeable with those of the 
teachers. However, very little appears to have changed with respect to the recruitment and management of TAs. Despite Butt and Gunter's (2007) assertion that 'teachers... and policy makers can take lessons from the past to inform current practice and decision making' (p.187), austerity measures put into place over the past six years by the Coalition and Conservative governments have greatly reduced funding, dramatically cutting TA numbers and changing working practices in schools.

The almost complete eradication of the LAs' role in the training and deployment of TAs is recognised in the following statement from a headteacher involved in this study:

'I haven't had any input from the Local Authority with regards to TA management.

We're given a budget and have to do the best we can with it' $(\mathrm{H}, \mathrm{m}, 3)$

The problems of TA management and deployment will not yield to simple technicist solutions, nor to assertions that TA practice simply needs 'tightening up' (Blatchford et al, 2012, p.122). Such declarations, often favoured by 'how to get the best out of your TA' type guides (Clark et al 1999), rarely question the status quo nor look to the solution of long standing issues of employment structures, conditions of service and finance. Watkinson (2003) argues that creative TA deployment could open up 'a whole new vision of education in the twenty-first century', while Emam and Farrell (2009) call for a move away from 'short-term, pull-out, add-on' (p.149) interventions - in favour of the reconceptualization of dedicated teacher support. The introduction of Education Health and Care Plans (EHCPs) replacing statements in SEN provision will likely be expressed in terms of hours allocated for TA (and other) support. However, we would argue that similar to pupil premium payments (introduced in 2011), which were used to pay TAs to support low attainers, this will do little to change the ways in which TAs are led, deployed and managed. We conclude that the deployment, management and leadership of TAs in many schools is still haphazard, relying on good intentions rather than strategic imperatives. 


\section{References}

Alborz, A., Pearson, D., Farrell, P. and Howes, A. (2009) The impact of adult support staff on pupils and mainstream schools, London: DCFS and Institute of Education.

Blatchford, P, Russell, A and Webster, R (2011), Effective Deployment and Teaching Assistants:

Challenging The Role and Deployment of Teaching Assistants in Mainstream Schools: The Impact on Schools EDTA Report [Online] School Support Staff. Net, London: Available from:

http://www.schoolsupportstaff.net/edtareport.pdf [Accessed 6 June 2013)

Blatchford, P, Russell, A and Webster, R (2012), Reassessing the Impact of Teaching Assistants. London: Routledge Fulton.

Booth, T and Ainscow, M (2002) Index for Inclusion: Developing learning and participation in schools, http://www.csie.org.uk/publications (accessed 25th August 2014)

Bullock, A, Firmstone, V, Frame, J and Thomas, H (2010) Using dentistry as a case study to examine continuing education and its impact on practice. Oxford Review of Education, 36 (1) pp.79-95.

Butt, G and Gunter, H (eds) (2007), Modernizing Schools: people, learning and organisations, London: Continuum.

Butt, G and Lance, A, (2009) 'I am not the teacher!': some effects of remodelling the roles of teaching assistants in English Primary Schools', Education 3-13, 37 (3) pp. 219-231.

Butt, G , Lance, A, Fielding, A, Gunter,H, Rayner, S, and Thomas, H (2005) Teacher job satisfaction: lessons from the TSW Pathfinder Project. School Leadership and Management. Vol 25 (5) p.455-471.

Butt, G and Macnab, N (2013) Making connections between the appraisal, performance management and professional development of dentists and teachers: 'we sat down and we talked, and we've never formally sat down and talked before'. Professional Development in Education. Vol (39) 5 pp.841-861 
Clark, C, Dyson, A, Millward, A and Robson, S (1999) Theories of inclusion, Theories of Schools: deconstructing and reconstructing the 'inclusive school', British Educational Research Journal, Vol. 25, No. 2, pp. $157-177$.

Clayton, $T$ (1993) 'From domestic helper to 'assistant teacher' - the changing role of the British classroom assistant', European Journal of Special Needs Education, Vol 8, 1 pp 32-44

Cremin, H, Thomas, G and Vincett, K (2005) Working with Teaching Assistants: Three Models Evaluated, Research Papers in Education, 20(4) pp. 413-432

DES (1978) Warnock Report: Report of the Committee of Enquiry into the Education of Handicapped Children and Young People. London: Her Majesty's Stationery Office.

DfE (2011) Support and Aspiration: a new approach to special educational needs and disability. A consultation (Green Paper) Cm8027, London: HMSO [online] http://www.education.gov.uk/publications/standard/publicationDetail/Page1/CM\%208 027 [Accessed 21.6.12]

DfE (2014) SEN/D Code of Practice, Guidance on the special educational needs and disability (SEND) system for children and young people aged 0 to 25 . Ref: DFE-00205-2013

DfES (1981) Education Act: An Act to make provision with respect to children with special educational needs. London: Her Majesty's Stationery Office.

DfES (2000) Working with Teaching Assistants: a Good Practice Guide, DfES 0148 / 2000, London: Her Majesty's Stationery Office.

DfES (2002) Education Act: An Act to make provision about education, training and childcare, London: Her Majesty's Stationery Office.

Dillow, C (2010) Supporting Stories: Being a Teaching Assistant. Stoke on Trent: Trentham 
Dymoke, S, and Harrison, J (2008) Reflective Teaching and Learning, London: Sage Publications Ltd

Elkins, A and Grimes, P (2009) Inclusion: developing an effective whole-school approach

Maidenhead: Open University Press

Everard, K, Morris, G and Wilson, I (2004), Effective School Management, 4th Edition . K. B.

Everard Paperback

Fletcher-Campbell, F, (2010) Double Standards and First Principles: Framing Teacher Assistant Support for Pupils with Special Educational Needs: a Response, European Journal of Special Needs Education 25 (4), pp 339-340

Giangreco, M (2010) Utilisation of Teacher Assistants in Inclusive Schools: is it the Kind of Help that Helping is All About? European Journal of Special Needs Education, 25 (4), pp.341-345

Goepel, J and Sharpe, S (2014) Inclusive Primary Teaching: A Critical Approach to Equality and Special Educational Needs (Critical Teaching), Northwich: Critical Publishing

Gunter, H., (2007), Remodelling the School Workforce in England: a Study in Tyranny, Journal for Critical Education Policy Studies, 5, pp.1-11

Higgins, Katsipataki, M, Kokotsaki, D, Coe, R, Major, L and Coleman, R (2003) The Sutton TrustEducation Endowment Foundation Teaching and Learning Toolkit

HMI, (2002) Teaching Assistants in Primary Schools: and Evaluation of the Quality and Impact of Their Work, HMI 434, London: Her Majesty's Stationery Office.

House of Commons (2011), Hansard, parliamentary written answer, www.publications.parliament.uk/pa/cm201011/cmhansard/cm110909/text/110909w0003.htm\#110 $\underline{90989000157}$ (Accessed 9th September 2013) 
Kamen, T, (2003) Teaching Assistant's Handbook, Oxford: Hodder and Stoughton

Klassen, R (2001) After the statement: Reading progress made by secondary students with specific literacy difficulty provision, Educational Psychology in Practice, 17, (2), pp.121-133.

Lehane, T (2016) "Cooling the mark out": experienced teaching assistants' perceptions of their work in the inclusion of pupils with special educational needs in mainstream secondary schools, Educational Review, Vol 68, (1), pp. 4-23

Lepkowska, D (2013) Anger as Treasury eyes-up cuts to teaching assistants. [Online] Available from:http://www.sec-ed.co.uk/news/anger-as-treasury-eyes-up-cuts-to-teaching-assistants [Accessed 02.11.03]

Mahmood, E (2011) I am more than just a TA! Management in Education, Sage Publications, Ltd.

Mansaray, A (2006) Liminality and In/Exclusion: Exploring the Work of Teaching Assistant, Pedagogy, Culture and Society, $14(2)$, pp.171-187.

Martin, C, Russell, A, and Webster, R, (2009) Deployment and Impact of Support Staff Project, DCSF

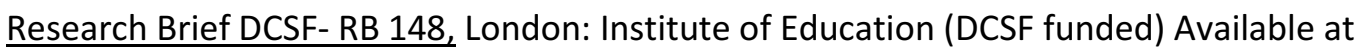
http://www/ioe.ac.uk/DISS Research Summary.pdf (Accessed 23 June 2014) Myatt, G (2007) Making Sense of Data: A Practical Guide to Exploratory Data Analysis and Data Mining: Hoboken, NJ: Wiley NASUWT (2014) Teachers Briefing on SEN/D reforms, [Online], Available from: http://www.nasuwt.org.uk/consum/groups/public/@education/documents/nas_download/nasuwt _012883.pdf

Ofsted (2002) The Teaching Assistant in Primary Schools: An evaluation of the quality and impact of their work, London: Her Majesty's Inspectorate of Education 
Ofsted (2012) The framework for school inspection from January 2012 [Online] Available from: http://www.ofsted.gov.uk/resources/framework-for-school-inspection-january-2012 [Accessed 02.10.13]

O’ Reilly, K (2009) Key Concepts in Ethnography, London: Sage.

Pearson, S, Chambers, G and Hall, K (2003) Video Material as a Support to Developing Effective Collaboration Between Teachers and Teaching Assistants, Support for Learning, 18 (2), pp.83-87 Plowden Report (1967) Children and their Primary Schools, A Report of the Central Advisory Council for Education (England), London: Her Majesty's Stationery Office 1967

Pole, C and Morrison, M (2003) Ethnography for Education, Maidenhead: Open University Press.

Pugh, J (2007) How are primary school teaching assistants being managed, motivated and led since the implementation of the National Workforce Agreement in 2003?, Paper resented at BERA conference.

Pyke (2004)

Russell, A, Webster, R and Blatchford, P (2013) Maximising the Impact of Teaching Assistants.

Oxford: Routledge

Sharples, E, Webster, R., Blatchford, P. (2015) Making Best Use of Teaching Assistants Guidance Report, London: Education Endowment Foundation

Sutton Trust Review (2012) What makes great teaching? Review of the underpinning research London: Sutton Trust

Swann, W and Loxley, A (1998) The Impact of School-Based Training on Classroom Assistants in Primary School, Research Papers in Education, 13 (2) pp. 141-160 
Taylor, C (2001) Sources of the Self: The Making of the Modern Identity, Cambride MA: Harvard University Press

Thornton, M and Hedges, C (2006), The Active Engagement of Teaching Assistants in Teaching and Learning, National Teacher Research Panel: Engaging Teacher Expertise, http://www.ntrp.org.uk/node/76 (accessed 24th January 2014)

Thorpe, L, Trewhitt, K and Zuccollo, J (2013) Must do better: Spending on schools, http://socialwelfare.bl.uk/subject-areas/services-activity/educationskills/reform/147441Must_do_better_Spending_on_schools.pdf

Watkinson, A (2003) Managing Teaching Assistants: A Guide for Headteachers, Managers and Teachers, London: Routledge Falmer

Watkinson, A (2008) Leading and Managing Teaching Assistants: a Practical Guide for School Leaders, Teachers and Higher-Level Teaching Assistants, Abingdon: David Fulton Webster, A and Blatchford, P (2015) Worlds apart? The nature and quality of the educational experiences of pupils with a statement for special educational needs in mainstream primary schools, British Educational Research Journal, Volume 41, Issue 2, pp 324-342.

Wright, J and Kersner, M (2001) Supporting Children with Communication Problems: Sharing the Workload. London: David Fulton. 